\title{
Corrigendum: U2-U6 RNA folding reveals a group II intron-like domain and a four-helix junction
}

\author{
Dipali G Sashital, Gabriel Cornilescu \& Samuel E Butcher \\ Nat. Struct. Mol. Biol. 11, 1237-1242 (2004).
}

The manuscript contained a description of, as well as data and conclusions derived from, a U2-U6 RNA (the 110-nucleotide RNA) that was conceived, created and supplied by C. Joel McManus (C.J.M.) and David A. Brow (D.A.B.). Although C.J.M. was acknowledged in the original version, both C.J.M. and D.A.B should have been included as authors. To correct this oversight, the full author list should read: Dipali G Sashital, Gabriel Cornilescu, C Joel McManus, David A Brow \& Samuel E Butcher.

C.J.M. and D.A.B. have read and approved of the manuscript, with the following three corrections. First, in the Results section (page 1238, second column, "Comparison of the U6 ISL and D5," fourth sentence), the third base pair in the list is incorrect. The corrected sentence should read: "When the AGC triad is included within the ISL, the three base pairs that form at the base of the ISL (A59-U88, G60•U87 and C61-G86) are identical to the nearly invariant base pairs of D5." Second, in the Methods section (page 1241, "NMR sample preparation," line 4), the description of how the RNAs were generated is incomplete. The 73-, 81-, and 101-nucleotide RNAs were generated as run-off transcripts after plasmid digestion with BsaI enzyme as stated in the original manuscript. However, the 3 ' end of the 110-nucleotide RNA was formed via cotranscriptional hammerhead cleavage. Lastly, the Acknowledgments section (page 1241) should read: "We thank M. Tonelli and the National Magnetic Resonance Facility (NMRFAM) staff for technical support. NMR studies were carried out at NMRFAM with support from the US National Institutes of Health (NIH) Biomedical Technology Program and additional equipment funding from the University of Wisconsin, the US National Science Foundation (NSF) Academic Infrastructure Program, the NIH Shared Instrumentation Program, the NSF Biological Instrumentation Program, and the US Department of Agriculture. This investigation was supported by NIH grant GM65166 to S.E.B., by NIH grant GM54018 to D.A.B., and by NIH predoctoral training grant T32 GM007215 to D.G.S and C.J.M.” We apologize for any inconvenience this may have caused. 